\title{
A quality improvement project on adherence to antibiotic policy in acute admissions from a tertiary care hospital in south India
}

\author{
Authors: Roshni Pillay, ${ }^{A}$ Balram Rathish, ${ }^{A}$ Arun Wilson, ${ }^{B}$ Anup Warrier ${ }^{C}$ and Geetha Mary Philips ${ }^{D}$
}

\begin{abstract}
The indiscriminate use of antibiotics in clinical practice may be an independent risk factor for the development of antimicrobial resistance. To combat this, our hospital implemented a hospital antibiotic policy which outlines the appropriate antibiotic to be used in an acute admission, based on a continuously updated local antibiogram. However, we felt that compliance with the policy was poor and hence carried out a quality improvement project (QIP) to assess and increase compliance. We show that a simple QIP model combined with the use of a mobile application can serve to improve compliance even in a lowresource setting with minimum infrastructure. This model could be easily extrapolated into similar settings.
\end{abstract}

KEYWORDS: antibiotic policy, antibiogram, compliance, quality improvement, mobile application

DOI: $10.7861 /$ clinmed.2020-0253

\section{Introduction}

South Asia has been possibly at the highest risk globally for the development of antimicrobial resistance (AMR), due to rampant and indiscriminate use of antibiotics in the medical as well as veterinary sectors. ${ }^{1}$ It is still quite common to see prescribers not adhering to any particular guidelines when prescribing antibiotics to patients, which again adds to the burden of AMR. To combat this, our hospital implemented a hospital antibiotic policy which outlines the appropriate antibiotic to be used in an acute admission, based on a continuously updated local antibiogram. However, we felt that compliance with the policy was poor and hence carried out a quality improvement project (QIP) to assess and increase compliance. While published literature on use of mobile applications as an intervention in a similar setting is scarce, the available literature has shown a potential benefit, and hence

Authors: ${ }^{\text {A }}$ core medical trainee-3, Aster Medcity, Kochi, India; ${ }^{B}$ specialist in infectious diseases, Aster Medcity, Kochi, India; ${ }^{C}$ lead consultant in infectious diseases, Aster Medcity, Kochi, India; 'Dlead senior consultant in internal medicine and programme director, Aster Medcity, Kochi, India the use of such an application was one of our major interventions, along with regular prescriber educational sessions. ${ }^{2,3}$

The QIP aimed to measure the compliance of the prescribers to the antibiotic policy during these acute admissions and to intervene in the event of suboptimal compliance.

\section{Methods}

This study was conducted in a tertiary care centre in south India as a quality improvement project with prospective audit and feedback, and two plan, do, study, act (PDSA) cycles. The study period was 10 November 2018 to 04 February 2020. The initial audit was conducted between 10 November 2018 and 09 December 2018. After the intervention, the re-audit was conducted between 05 January 2020 and 04 February 2020

The inclusion criteria for the study consisted of any patient aged above 16 years who was admitted through acute admission and who was started on an empirical antibiotic(s) at the time of admission. The exclusion criteria consisted of paediatric patients aged less than 16 years, pregnant women and any patient who was currently on an antibiotic started at another centre at the time of acute admission (pregnant women were excluded as some antibiotics in the policy may be contraindicated during pregnancy). The prescriber pool consisted of 36 doctors who were involved in acute admissions.

The hospital antibiotic policy was developed based on a locally developed hospital-specific antibiogram built using data obtained from microbiological sampling of patients. The policy specifies that the empiric therapy of infections should be based on the possible clinical syndrome, primary site of infection and the possible pathogens, taking into account the risk of drug-resistant pathogens based on host characteristics and disease severity. In the policy, for convenience and simplicity, patients are classified into four types based on these parameters and antimicrobial suggestions were provided accordingly.

> Type 1: Community-acquired infection in a normal host with no haemodynamic instability.

> Type 2: Community-acquired infection in a host who is immunocompromised due to comorbidity and/or medications OR healthcare-associated infection in a normal, haemodynamically stable host OR community-acquired infection in a normal host with haemodynamic instability. 
Table 1. Hospital antibiotic policy showing recommended empirical antibiotic regimen based on clinical syndrome and type of patient

\begin{tabular}{|c|c|c|c|c|}
\hline & Type 1 & Type 2 & Type 3 & Type 4 \\
\hline $\begin{array}{l}\text { Meningo- } \\
\text { encephalitis }\end{array}$ & $\begin{array}{l}\text { Ceftriaxone with } \\
\text { doxycycline }+ \\
\text { artesunate }+ \text { acyclovir }\end{array}$ & $\begin{array}{l}\text { Piperacillin-tazobactam + } \\
\text { vancomycin + acyclovir }\end{array}$ & $\begin{array}{l}\text { Meropenem + vancomycin/ } \\
\text { linezolid }\end{array}$ & $\begin{array}{l}\text { Liposomal } \\
\text { amphotericin-b or } \\
\text { flucanozole }\end{array}$ \\
\hline $\begin{array}{l}\text { Focal brain } \\
\text { lesion }\end{array}$ & $\begin{array}{l}\text { Ceftriaxone }+ \\
\text { metronidazole }+ \\
\text { vancomycin }\end{array}$ & $\begin{array}{l}\text { Piperacillin-tazobactam + } \\
\text { linezolid }\end{array}$ & Meropenem + linezolid & $\begin{array}{l}\text { Liposomal } \\
\text { amphotericin-b or } \\
\text { flucanozole }\end{array}$ \\
\hline Sinusitis & $\begin{array}{l}\text { Amoxicillin-clavulanic } \\
\text { acid or clarithromycin }\end{array}$ & $\begin{array}{l}\text { Piperacillin-tazobactam + } \\
\text { azithromycin }\end{array}$ & Meropenem + linezolid & $\begin{array}{l}\text { Liposomal } \\
\text { amphotericin-b }\end{array}$ \\
\hline $\begin{array}{l}\text { Acute bronchitis / } \\
\text { COPD } \\
\text { exacerbation }\end{array}$ & $\begin{array}{l}\text { Clarithromycin or } \\
\text { amoxicillin-clavulanic } \\
\text { acid }\end{array}$ & $\begin{array}{l}\text { Cefaperazone-sulbactum + } \\
\text { azithromycin }\end{array}$ & Consult infectious diseases & Not applicable \\
\hline Pneumonia & $\begin{array}{l}\text { Amoxicillin-clavulanic } \\
\text { acid }+ \text { azithromycin }+ \\
\text { consider oseltamivir }\end{array}$ & $\begin{array}{l}\text { Consider MRSA cover }+ \\
\text { cefaperazone-sulbactum }+ \\
\text { azithromycin cotrimoxazole at } \\
\text { high doses if PCP is suspected } \\
\text { in HIV }\end{array}$ & $\begin{array}{l}\text { Imipenem }+ \text { linezolid }+ \\
\text { levofloxacin or tigecycline }+ \\
\text { colistin }\end{array}$ & $\begin{array}{l}\text { Caspofungin or } \\
\text { voriconazole }\end{array}$ \\
\hline $\begin{array}{l}\text { Intra-abdominal } \\
\text { infections }\end{array}$ & $\begin{array}{l}\text { Cefaperazone-sulbactum } \\
\text { or ertapenem }\end{array}$ & $\begin{array}{l}\text { Imipenem or tigecycline alone; } \\
\text { ertapenem if haemodynamically } \\
\text { stable }\end{array}$ & $\begin{array}{l}\text { Imipenem/doripenem }+ \\
\text { teicoplanin } \\
\text { consider tigecycline }+ \text { colistin }\end{array}$ & $\begin{array}{l}\text { Caspofungin or } \\
\text { anidulafungin }\end{array}$ \\
\hline $\begin{array}{l}\text { Urinary tract } \\
\text { infections }\end{array}$ & $\begin{array}{l}\text { Cefaperazone-sulbactum } \\
\text { or amikacin }\end{array}$ & $\begin{array}{l}\text { Cefaperazone-sulbactum + } \\
\text { amikacin or meropenem }\end{array}$ & $\begin{array}{l}\text { Doripenem/meropenem + } \\
\text { teicoplanin/vancomycin }\end{array}$ & $\begin{array}{l}\text { Flucanozole } \\
\text { or liposomal } \\
\text { amphotericin-b or } \\
\text { caspofungin }\end{array}$ \\
\hline $\begin{array}{l}\text { Skin and soft } \\
\text { tissue infections }\end{array}$ & $\begin{array}{l}\text { Amoxicillin-clavulanic } \\
\text { acid or clindamycin }\end{array}$ & $\begin{array}{l}\text { Amoxicillin-clavulanic acid } \\
\text { or piperacillin-tazobactam }+ \\
\text { linezolid/teicoplanin or tigecycline } \\
\text { alone }\end{array}$ & $\begin{array}{l}\text { Imipenem + linezolid/ } \\
\text { teicoplanin or tigecycline }+ \\
\text { colistin }\end{array}$ & $\begin{array}{l}\text { Liposomal } \\
\text { amphotericin-b or } \\
\text { voriconazole }\end{array}$ \\
\hline $\begin{array}{l}\text { Bone and joint } \\
\text { infections }\end{array}$ & $\begin{array}{l}\text { Ceftriaxone }+ \\
\text { teicoplanin }\end{array}$ & $\begin{array}{l}\text { Cefaperazone-sulbactum }+ \\
\text { teicoplanin }\end{array}$ & $\begin{array}{l}\text { Tigecycline + colistin or } \\
\text { meropenem + teicoplanin }\end{array}$ & $\begin{array}{l}\text { Liposomal } \\
\text { amphotericin-b or } \\
\text { caspofungin }\end{array}$ \\
\hline $\begin{array}{l}\text { Occult sepsis / } \\
\text { blood stream } \\
\text { infection }\end{array}$ & $\begin{array}{l}\text { Ceftriaxone }+ \\
\text { azithromycin }+ \\
\text { artesunate }\end{array}$ & $\begin{array}{l}\text { Cefaperazone-sulbactum }+ \\
\text { amikacin or ertapenem; add } \\
\text { azithromycin to either }\end{array}$ & $\begin{array}{l}\text { Meropenem + teicoplanin/ } \\
\text { vancomycin }\end{array}$ & $\begin{array}{l}\text { Caspofungin or } \\
\text { anidulafungin }+1- \\
\text { voriconazole }\end{array}$ \\
\hline
\end{tabular}

$\mathrm{COPD}=$ chronic obstructive pulmonary disease; $\mathrm{MRSA}$ = methicillin-resistant Staphylococcus aureus; $\mathrm{PCP}$ = pneumocystis pneumonia.

> Type 3: Healthcare-associated infection with severe sepsis OR community-acquired infection in immunocompromised hosts with haemodynamic instability OR multi-organ dysfunction syndrome.

> Type 4: Host factors and clinical syndrome suggesting possible fungal aetiology.

Based on the type of patient and the site of the infection, broad categories were identified to be included in the policy (blood stream infections, respiratory infections, intra-abdominal infections, urinary tract infections, skin and soft tissue infections, etc; see Table 1). Sepsis was defined as life-threatening organ dysfunction caused by a dysregulated host response to infection with evidence of a focus of infection with haemodynamic instability. ${ }^{4}$

After the initial audit was conducted to measure the extent of the identified problem, the interventions were spaced out over the course of the next year and included multiple prescriber education sessions about the existence and content of the antibiotic policy, emailing copies of the policies to all stakeholders involved in prescribing, making a printed copy of the antibiotic policy available in the acute admission unit, and, finally, giving all prescribers access to a mobile application called 'DigitalAMS' that presents the antibiotic policy in an easy-to-use manner (www.msdhealthassist.com/mha). The mobile application was developed by Merck \& Co (MSD) for the purpose of assisting antibiotic prescription. Our local antibiogram and policy were uploaded onto the DigitalAMS server and the application's recommendations were customised according to our institution's policy.

Once given access to the application by a local administrator, the prescriber will have to input three variables: the patient type, which corresponds to the aforementioned type from the hospital antibiotic policy; the haemodynamic stability of the patient, based 
on whether the patient is being admitted to a ward or intensive care unit; and finally the site of infection. Since intra-abdominal infection was not a category on the mobile application but commonly encountered in the initial audit, special emphasis was given to educating prescribers on the recommended antibiotic in this infection during the intervention sessions.

The outcome measures used were compliance to the antibiotic policy, average length of hospital stay (LOS) during the current admission (which may be an indirect measure of better clinical outcomes secondary to treatment with appropriate antibiotics), the clinical outcome of the patient measured by clinical condition at the 1-month outpatient follow-up (where the clinical condition was assessed subjectively by the consultant treating the patient), and re-admission related to primary admission episode within 1 month.

The process measure used to assess policy compliance was auditing the medication chart to check for recording of whether the prescribed antibiotic was empirical vs definitive and of the site of infection. The balancing measure was whether microbiological cultures were sent prior to administering empirical antibiotics. The authors felt that in the process of providing a guide to prescribing an antibiotic agent based on the aforementioned criteria, the prescribers might forego microbiological sampling as an unintended consequence.

The data collection was done exclusively by the lead investigators on a daily basis to avoid sampling bias. We reviewed the patients' medication charts, which were filled in by the prescriber, and crosschecked this against the hospital electronic medical records. This data collection was done within 24 hours of first admission of the patient. The data was entered into MS Excel 2016 and conclusions drawn. There were no ethical implications identified in our study and although ethical committee clearance was not deemed necessary, clearance was obtained from the quality department at the onset of the study.

The first PDSA cycle of the QIP was completed by presenting the results of the audit to the stakeholders involved and educating them on the existence of and need for compliance to the policy. At this point, the mobile application DigitalAMS was introduced. The 36 prescribers who were directly involved with the acute admissions were given exclusive access to the application through our local administrator. Repeated sessions were conducted over the course of 1 year with the prescribers and other stakeholders, including training on the usage of the application and discussion about the hospital antibiotic policy. The results of the re-audit were presented and discussed with the relevant stakeholders.

\section{Results}

In our initial audit of admissions over the course of 1 month, between 10 November 2018 to 09 December 2018, 111 patients were acutely admitted. Out of these, 67 (60\%) patients received empiric antibiotics and were audited. The cases broadly consisted of 34 respiratory infections, 10 cases of urinary tract infections, eight cases of undifferentiated fever with no obvious focus, seven cases of skin and soft tissue infection, four cases of abdominal infections, two cases of sepsis with multi-organ dysfunction and two cases of neutropenic sepsis. We found that only 10 (15\%) of the patients received an appropriate agent as per the policy. 40 cases received an antibiotic from the lower patient type than what was recommended by the policy. Microbiological sampling for bacterial cultures was not carried out in seven (10.5\%) cases
Table 2. Comparison between outcome measures,

process measures and balancing measures in

the audit and re-audit stages of the quality

improvement project

\begin{tabular}{|c|c|c|}
\hline & Audit & Re-audit \\
\hline Number of patients audited, $n$ & 67 & 61 \\
\hline Adherence to policy, n (\%) & $10(15)$ & $32(52.5)$ \\
\hline $\begin{array}{l}\text { Microbiological sampling not sent, } \\
\mathrm{n}(\%)\end{array}$ & $7(10.5)$ & $13(21)$ \\
\hline Medication chart completed, n (\%) & $43(64)$ & $50(82)$ \\
\hline Prolonged hospital stay, n (\%) & $9(13)$ & $5(8)$ \\
\hline Clinically better at 1 month, $\mathrm{n}(\%)$ & $49(73)$ & $45(73)$ \\
\hline $\begin{array}{l}\text { Re-admitted in less than } 1 \text { month, } \\
\text { n (\%) }\end{array}$ & $6(9)$ & $0(0)$ \\
\hline Lost to follow-up, n (\%) & $12(18)$ & $16(26)$ \\
\hline
\end{tabular}

prior to initiation of empirical antibiotic therapy. The medication chart, including the columns for indication of the agent, whether the prescribed antibiotic was empirical vs definitive, and the site of infection, was completely filled in in only $43(64 \%)$ cases. The average LOS was found to be 5.9 days. All 67 of these patients were discharged without complications. Fifty-eight patients were discharged within 7 days and were clinically better at discharge while nine $(13 \%)$ patients required prolonged hospital stay $(>7$ days). Clinical follow-up after a month showed that $49(73 \%)$ patients were reported to be clinically better while $12(18 \%)$ patients did not follow up. Six (9\%) patients were re-admitted within a month (Table 2).

The second PDSA cycle was initiated with re-audit beginning on 05 January 2020 and completed on 04 February 2020. A total of 102 patients were acutely admitted, out of which 61 (60\%) patients received empiric antibiotics and were audited. The cases broadly consisted of 24 cases of respiratory infections, 17 cases of abdominal infections, 10 cases of urinary tract infections, four cases of skin and soft tissue infections, three cases of undifferentiated fever with no obvious focus, two cases of sepsis with multi-organ dysfunction and one case of a snake bite. We found that 32 (52.5\%) patients received appropriate antibiotics as per policy. Microbiological sampling in the form of sample for bacterial cultures were not sent in $13(21 \%)$ cases prior to initiation of empirical antibiotic therapy. The medication chart, including the columns for indication of the agent, whether the prescribed antibiotic was empirical vs definitive, and the site of infection, was completely filled in in 50 (82\%) cases. The average LOS was found to be 4.9 days. All 61 of these patients were discharged without complications. Fifty-five patients were discharged within 7 days and were clinically better at discharge while five ( $8 \%)$ patients required prolonged hospital stay ( $>7$ days). Clinical follow-up after a month showed that showed $45(73 \%)$ patients reported to be clinically better while 16 (26\%) patients did not follow up. There were no re-admissions within 1 month (Table 2).

\section{Discussion}

With respect to the outcome measures, our audit found that compliance to the hospital policy was only $\sim 15 \%$ in acute 
admissions. With simple interventions, which included multiple sessions of prescriber education and the introduction of a mobile application based on a hospital-specific antibiogram, compliance increased to $52.5 \%$ in 1 year. The intervention also succeeded in reducing average LOS by 1 day from 5.9 days to 4.9 days. In the indicators of clinical outcome of the patients, the proportion of patients who reported to be clinically better at 1-month follow-up remained stable at $73 \%$, but no patients were re-admitted during the re-audit as compared with a $9 \%$ re-admission during initial audit and only $8 \%$ of patients required a prolonged hospital stay as compared with $13 \%$ in the initial audit. There were a higher number of patients who did not follow up during the second PDSA cycle, which could have been a confounding factor.

In the process measures, in the initial audit, only $64 \%$ of the cases had a completely filled-in antibiotic chart, with the columns for indication of the agent, whether the prescribed antibiotic was empirical vs definitive, and site of infection all completed. With the intervention, this increased to $82 \%$. Another process measure we wanted to measure was the usage of the DigitalAMS application, but unfortunately such data couldn't be accessed.

The balancing measure of microbiological sampling showed an unintended jump following our interventions. In the initial audit, only $10.5 \%$ of patients had no microbiological cultures sent prior to administration of empirical antibiotic, but this increased to $21 \%$ in the re-audit, most likely as a consequence of prescribers feeling that it was not indicated as the application gave a specific antibiotic regimen based on hospital antibiogram. This was particularly important as bacterial-culture-based definitive therapy is an important factor in reducing potential AMR.

The improvement in our compliance was higher than the results declared by Yoon et al in their study. ${ }^{2}$ Theirs was a similar study in the form of an audit with prospective feedback and introduction of a (different) mobile application, but also included a control group in different hospitals. They also audited only two infectious syndromes compared with our study, whereas we included all patients who received empirical antibiotics. The possible reason for our increased compliance rate could be the smaller prescriber pool of 36 doctors limited to a single hospital, compared with their prescriber pool of 145 . Yoon et al concluded that the introduction of a mobile phone application is not sufficient to achieve high levels of prescriber adherence. Our study shows a stark contrast to these findings, which can most likely be attributed to the repeated sessions of training about the application, education on the antibiotic policy and structured prospective feedback in a QI model.

Charani et al found a similar intervention where a mobile application increased compliance, but there was a significant increase in compliance in only certain departments of their centre and their intervention was aimed at inpatients as part of their antimicrobial stewardship. ${ }^{3}$ In our study, a similar patient stratification was not possible as we concentrated on empirical therapy at the time of admission. We were also able to demonstrate a significantly higher increase in compliance compared with their study, likely due to intervention at an earlier stage of patient admission, but it could also be attributed to very low compliance levels in the initial audit.

Our study does have its limitations. The initial audit showed that compliance was poor at $15 \%$, but it did also show that a majority of patients were receiving antibiotics from a lower group than what was suggested by the policy. This was attributed to the inclusion of patients with well-controlled diabetes into a higher group along with patients with poorly controlled diabetes. Despite this, the clinical outcomes did not show a difference in the re-audit where compliance had increased threefold. This could be an indication for revision of the policy to re-categorise patients with well-controlled diabetes into lower group. In the use of LOS as an outcome measure, we were not able to match the patients to avoid confounders. We also found an unintended jump in the balancing measure of decreased microbiological sampling, which could have been partly as a result of inadequate education on this during the interventional sessions with the prescribers. Another limitation of our study was the inability to measure the process measure of number of times or frequency of the prescribers accessing the application.

\section{Conclusion}

We feel that our QI model intended to increase compliance to an antibiotic policy is an easy-to-reproduce, low-resource-dependent, low-cost model that can be easily replicated in any setting globally. Simple measures such as repeated prospective feedback cycles, multiple educational sessions with involved stakeholders and the introduction of a low-cost intervention (eg a mobile application) can serve to improve quality of medical care in the form of increased compliance to a uniform policy in prescription of antibiotics, reduction in average LOS and quite possibly better clinical outcomes by virtue of appropriate empirical antibiotic therapy. :

\section{Acknowledgements}

We would like to thank Merck \& Co (MSD) for allowing the use of the application for the purpose of this study.

\section{References}

1 Singh PK. One health approach to tackle antimicrobial resistance in South East Asia. BMJ 2017;358:j3625.

2 Yoon CH, Ritchie SR, Duffy EJ et al. Impact of a smartphone app on prescriber adherence to antibiotic guidelines in adult patients with community acquired pneumonia or urinary tract infections. PLoS One 2019;14:e211157.

3 Charani E, Gharbi M, Moore LS et al. Effect of adding a mobile health intervention to a multimodal antimicrobial stewardship programme across three teaching hospitals: an interrupted time series study. J Antimicrob Chemother 2017;72:1825-31.

4 Singer M, Deutschman CS, Seymour CW et al. The Third International Consensus Definitions for Sepsis and Septic Shock (Sepsis-3). JAMA 2016:315:801-10.

Address for correspondence: Dr Balram Rathish, Aster Medcity, Kuttisahib Road Cheranelloor, South Chittoor, Kochi, Kerala 682027, India.

Email: balramrnair@gmail.com

Twitter: @Balramrnair 